\title{
Fundamentals of the Pediatric Consent Process
}

\section{in Louisiana}

\author{
Ashley Peairs, MD, ${ }^{1}$ Meredith Miceli, JD, ${ }^{2}$ Michael G. White, MD, ${ }^{3,4}$ Dominic S. Carollo, MD ${ }^{1,4}$ \\ ${ }^{1}$ Department of Anesthesiology, Ochsner Clinic Foundation, New Orleans, LA ²Department of Legal Affairs and Risk Management, \\ Ochsner Clinic Foundation, New Orleans, LA ${ }^{3}$ Department of Pediatric Cardiology, Ochsner Clinic Foundation, New Orleans, LA \\ ${ }^{4}$ The University of Queensland School of Medicine, Ochsner Clinical School, New Orleans, LA
}

\section{INTRODUCTION}

The principle of respect for persons-autonomydominates most conversations regarding ethical medical practice, and informed consent is the central tenet of most of these discussions. ${ }^{1,2}$ Along with the concept of informed consent as the expression of respect for persons comes the additional obligation to protect those who are not autonomous. Nowhere is this obligation more critical than in establishing the ethics for appropriate medical care of children who are not considered capable of autonomous behavior until they have matured and are considered to be incapable of providing informed consent. We explore the issues related to ethically appropriate medical consent to treat minor patients, with particular attention to the confines of Louisiana law.

\section{BEST INTEREST STANDARD FOR PEDIATRIC PATIENTS}

Most medical ethicists consider informed consent in the pediatric arena to be surrogate consent. With few exceptions, informed consent for children involves a proxy and the implicit belief that the proxy will assess the risks and benefits of any intervention and arrive at a decision that is in the best interests of the child. In the United States and most Western cultures, the best interest standard assigns this authority to the parents, in part because of the assumption that parents deeply care about their child and are therefore the most capable of making decisions in the best interests of the child. However, some dispute that the best interest standard is not perfectly applicable in the realm of pediatric medical care. We live in a cross-cultural society, and inherent in that reality is the fact that people can have radically different views about what counts as good and widely divergent perspectives on what is best. $^{3}$

Further, more than one person is often trying to make a decision for one patient. In such circumstances, conflict can arise about which choice is the solitary, standalone, best course for the patient. One person may focus exclusively on health concerns, while another person factors in other interests and/or goals for the patient. Many alternatives could be considered reasonable. When doctors maintain that their professional responsibility requires them to advocate for what is best, they put themselves in the position of not being able to tolerate any variation from their preferred course. Those providing medical care for children are not required to decide what an ideal choice is nor are they required to accept any choice that the parents choose., ${ }^{4,5}$ Instead, a middle path is proposed that provides a clear justification for determining which goals of care are rational and whether a parent's decision should be accepted or refused.

The driving force behind finding a resolution for the pediatric patient and his/her surrogate decision-makers should be the identification of not-unreasonable choices as opposed to striving for the best solitary choice ${ }^{4-6}$ The decisionmaking comes from 3 different domains. The first core domain, in which any reasonable person would agree with the decision (ie, a patient decides to undergo an appendectomy for a ruptured appendix), is straightforward. ${ }^{6}$ The second core domain includes a decision that any reasonable person would agree with, but values are prioritized differently and because of that prioritization, an alternate route is explored (ie, a family wishes to continue cancer treatment, but a teenager wishes to enter the palliative phase of treatment). The third core domain is idiosyncratic and isolated to a certain subset of the population (ie, a patient refuses blood products because of religious beliefs or refuses life-saving surgery because of a prohibition against body disfigurement). ${ }^{4}$

Another way to manage consent for medical treatment in the pediatric patient population is to adopt the three-box approach that can help guide medical professionals and caretakers of the child to a not-unreasonable choice as opposed to seeking an absolute best interest decision. In this model, the first and last boxes align with the first core domain of decision-making and the third core domain, respectively. The three-box approach has two extremes. The first extreme box is that no matter the treatment, the patient is likely to have a poor outcome (ie, chemotherapy for known terminal cancer). Physicians should support decision-making that does not prolong an agonizing death. The second and opposite extreme is the box for the cases in which a good outcome is likely (ie, thoracotomy for stage 1 lung cancer treatment). In this example, proxies should not be able to impose their personal values on another. Refusals in both of the extreme boxes are paradigmatically unreasonable because outcomes are likely not decision-dependent. When a decision-maker's choice disagrees with the treatment goal in these extreme boxes, physicians have a responsibility to their patients to reject the surrogate's decision. 
Physicians cannot and should not accept a surrogate's personal reasons for refusing significantly beneficial treatment when they determine that the surrogate's choice violates universal values. Pediatricians must refuse to honor the rejection of treatment that is likely to provide significant benefit to a pediatric patient. In these situations, informing the ethics committee or the local courts is helpful.

The most difficult situations are the situations in the middle box. The middle box contains medical decisions without significant consequences and decisions about treatments with uncertain outcomes. When a reasonable nonmedical person could accept or refuse the treatment option, medical teams should accept the decisions of the surrogates. Two further considerations persuade us to allow surrogate discretion for decisions in the middle box. First, the surrogate and the patient are likely to have similar cultural beliefs; therefore, decisions by the surrogate are more likely to reflect patient values than decisions made by cultural outsiders. Second, the family unit must bear the side effects of the treatment, the physical, financial, and moral burdens. Therefore, the right of decision-making should be given to those who have the responsibility for discharging the obligations. Once physicians determine that a decision belongs in the middle box, they should extend the presumption of reasonableness to acceptable surrogates and allow them to make decisions that reflect their values without physicians delving into their priorities or evaluating their reasons. In other words, if the situation has been sorted into the middle box, the surrogate's decision should be allowed to govern what is done as long as the decision is not unreasonable.

The pediatric patient is considered an integral part of the decision-making process. Within the limits of their ability to understand, children should not feel that medical intervention is a physical assault on their person. This concept is incorporated into the required process of obtaining assent from a child to participate in research or to undergo medical procedures, with some exceptions. Assent may not be legally required if the procedure is medically necessary, but the procedure should still be discussed with the child. This ethical obligation places a great responsibility on the medical provider to determine the appropriate level of communication in a developmentally diverse population.

\section{ASSENT FOR OLDER CHILDREN AND ADOLESCENTS}

Assent allows older children and adolescents to have a different role in the decision-making process than their younger counterparts. The goal is to have the child participate in the decision-making involved in his or her medical care as appropriate for the child's developmental stage.

Assent should include the following elements as described by the American Academy of Pediatrics policy, "Informed Consent, Parental Permission, and Assent in Pediatric Practice"2,3:

1. Provision of information: patients should have explanations, in understandable language, of the nature of the ailment or condition; the nature of proposed diagnostic steps and/or treatment(s) and the probability of their success; the existence and nature of the risks involved; and the existence, potential benefits, and risks of recommended alternative treatments (including the choice of no treatment).
2. Assessment of the patient's understanding of the above information.

3. Assessment, if only tacit, of the capacity of the patient or surrogate to make the necessary decision(s).

4. Assurance, insofar as is possible, that the patient has the freedom to choose among the medical alternatives without coercion or manipulation.

The difference in neurobiology and cognitive capacities between older teenagers and young adults is small. This fact has led to an interesting ethical question: who is the decision-maker? Do the parents have the legal decisionmaking authority or do adolescents deserve to be treated as autonomous medical decision-makers? The answer varies, depending on circumstances. However, one principle rings true: as minors approach the age of majority, their greater participation is sought in medical decision-making, more weight is given to their preferences, and more information is provided consistent with informed consent for more complex medical decisions. The amount of authority given to older minors for assent depends on the maturity of the patient and the extent of possible harm occurring from the decision.

\section{DECISION-MAKING CAPACITY EVALUATION}

An assessment of decision-making capacity is the most important aspect of determining the amount of authority granted to an adolescent. ${ }^{7-10}$ Four criteria can be used to determine decision-making capacity ${ }^{7,11}$ : (1) ability to understand and communicate information; (2) ability to think and choose with some degree of independence; (3) ability to assess the potential for benefit, risks, or harms as well as to consider consequences and multiple options; and (4) achievement of a fairly stable set of values.

Factors that influence these criteria are age, ability, experience, education, exhibited judgment, conduct, and the appreciation of relevant risks and consequences. ${ }^{12}$ An adolescent's ability to think about important medical decisions may be influenced too greatly by influences such as emotions, peer pressure, and outside appearance. In such cases, the medical team and surrogates should make decisions on an individual basis. $^{13,14}$

As stated above, the extent of harm of the decision is relevant in determining the authority given to the older minor. The outcome range, the possibility of long-term benefit, whether the outcomes are all acceptable, and the ability to rectify harms are assessed as the qualitative harm. The timing of a surgical correction can be delayed to attempt a nonsurgical correction as long as the surgical correction is still possible after the delay. Sometimes an operation can be postponed until the child reaches the age of majority at which point the patient can make an autonomous decision. A thorough discussion and evidence of mature decisionmaking capacity are warranted before permitting a complex decision that could result in harm.

Ideally, the best-interest-of-the-child decision-making of informed consent is a shared responsibility among the medical team, surrogates, and the patient. At times, however, surrogate consent may lead to conflict, particularly when the opinions of the provider, parents, and patient do not align. A physician has the challenging responsibility to identify situations in which the parents may be making decisions that do not represent the patient's best interest. One 
ethically well-explored example is the case of a child with parents who adhere to the belief that God prohibits transfusion, but the child requires a life-saving transfusion. Providers must carefully consider the potential psychological trauma and potential alienation of patient and family when taking the necessary legal steps to ensure adequate care for children in such circumstances. Consulting with medical, ethics, and legal experts at your institution in conflict situations is advised.

Privacy issues and sexual behavior are particularly sensitive areas of concern for clinicians providing care to older minors, specifically with regard to sharing information with the parent or guardian. The provider-patient relationship for this population is recognized in law with special provisions and guidance.

Finally, emancipated children under the recognized age of consent may present challenges to providing ethical care, and laws vary from state to state.

\section{REVIEW OF LOUISIANA LAWS AFFECTING CARE OF THE MINOR PATIENT Who Is a Minor?}

Laws governing consent for medical treatment of minors are state-specific. In Louisiana, a minor is a person under the age of 18 years, the age of majority in the state. Persons under the age of 18 years who are legally emancipated are considered majors for the purposes of medical consent. ${ }^{15}$

Emancipation for those younger than 18 years is obtained only via a court judgment or by virtue of marriage. ${ }^{16} \mathrm{~A}$ married minor who is divorced or widowed continues to maintain emancipated status. ${ }^{17}$ Pregnancy or childbirth does not result in emancipation, a fairly common misconception among healthcare providers and patients.

Louisiana is one of a small handful of states that allow minors, regardless of age or maturity, to consent to medical treatment. The public policy behind this allowance is obvious: the state wants its youngest citizens to be able to acquire necessary healthcare despite any negligence on the part of their parents in ensuring medical care for their children. This policy has led to a fairly generalized minor consent statute with little nuance, certainly none as to the ability of minors along the spectrum of age to weigh the considerations necessary for true, informed consent.

Legislatures and courts in some states have recognized the mature minor doctrine that allows an older adolescent judged capable of understanding information about the nature, risks, benefits, and alternatives of proposed healthcare to consent to or refuse such treatment. However, Louisiana has not yet recognized the doctrine, either statutorily or in court jurisprudence, aside from laws with respect to abortion and blood donation. ${ }^{18,19}$

\section{Minor Consent for General and Surgical or Invasive Healthcare}

In Louisiana, minors may consent to their own medical treatment in general when the minor is or believes himself or herself to be afflicted with an illness or disease. ${ }^{20}$ The law does not allow for minor consent to sterilization. The statute further allows minor consent for treatment intended to alleviate or reduce the pain, discomfort, or distress of labor and childbirth, including intravenous, intramuscular, epidural, or spinal medication administration. ${ }^{20}$ "No hospital and no physician licensed to practice medicine in this state shall incur civil or criminal liability in connection with any examination, diagnosis and treatment authorized by this [minor consent] section except for negligence." 20

While this statute is broadly written and refers to minors also being allowed to consent to surgical or invasive treatment, the practical application of the entirety of Louisiana's consent and contract laws generally results in the state's healthcare providers requiring written informed consent of parents or guardians for such procedures. ${ }^{21}$

Of course, the law of Louisiana, like other states, provides that consent to treatment for a patient of any age is implied when an emergency exists. ${ }^{22}$ Emergency is defined as a situation in which (1) in competent medical judgment, the proposed surgical or medical treatment or procedures are reasonably necessary; and (2) a person authorized to consent is not readily available, and any delay in treatment could reasonably be expected to jeopardize the life or health of the person affected or could reasonably result in disfigurement or impair faculties. ${ }^{22}$

\section{Minor Consent for Treatment of Drug Abuse and Sexually Transmitted Diseases}

Louisiana law expressly allows for minors to consent to their own treatment of drug abuse and sexually transmitted diseases. ${ }^{23,24}$ The state has no law specific to the prescription or administration of contraceptives, so such care falls under the general medical care statute, La. R.S $1079.1,{ }^{20}$ that allows minor consent. Louisiana does not currently have a provision explicitly authorizing minors to consent for mental health services.

\section{Minor Privacy}

If minors in Louisiana can consent to their own general medical care, do their parent(s) or guardian(s) have the right to be informed by the minor's healthcare provider? This decision is up to the discretion of the provider. La. R.S. 40:1079.1 provides that "[u]pon the advice and direction of a treating physician, or, in the case of a medical staff, any one of them, a physician or member of a medical staff may, but shall not be obligated to, inform the spouse, parent or guardian of any such minor as to the treatment given or needed, and such information may be given to, or withheld from the spouse, parent or guardian without the consent and over the express objection of the minor." 20

\section{Refusal of Care}

In Louisiana, only a person 18 years of age or older may refuse to consent to medical or surgical treatment. ${ }^{25}$ While parents and legal guardians have the right to refuse care for minors, they cannot do so if the refusal endangers the child's health. Louisiana healthcare providers may seek court intervention to order necessary treatment. Louisiana Children's Code article $1554^{26}$ provides as follows:

No child, including any infant born alive, shall be intentionally denied or deprived of any medical or surgical care by his parent, physician, or any other person when such medical or surgical care is necessary to 
attempt to save the life of the child in the opinion of a physician exercising competent medical judgment, except:

(1) When a child is in a continual profound comatose state and in the opinion of the child's physician, exercising competent medical judgment, he has no reasonable chance of recovery from that state despite every appropriate medical treatment to correct such condition, the child's parents and physician may discontinue the use of life-support systems or other medical treatment.

(2) When a child suffers from a terminal and irreversible condition despite every appropriate medical treatment to correct such condition, the child's parents and physician may discontinue the use of lifesustaining procedures or other medical treatment.

(3) When the potential risks to the child's life or health inherent in any treatment or surgery outweigh the potential benefits for survival from the treatment or surgery, a child's parents and physician may decline to provide potentially lifesaving medical or surgical care for the child.

Before the discontinuation of any medical care or treatment, the child must be diagnosed and certified in writing as qualifying within one or more of the exceptions above by two physicians who have personally examined the child, one of whom shall be the child's attending physician. $^{27}$

Notably, the Louisiana Children's Code, in its definition of child neglect, states that "[w]henever, in lieu of medical care, a child is being provided treatment in accordance with the tenets of a well-recognized religious method of healing which has a reasonable, proven record of success, the child shall not, for that reason alone, be considered to be neglected or maltreated."28 The law continues, "However, nothing herein shall prohibit the court from ordering medical services for the child when there is substantial risk of harm to the child's health or welfare."28

\section{Who Is a Parent or Guardian?}

The biological or adoptive parents of a child have the power to consent for his or her medical care. Both parents have equal say in the consent decision unless a court has expressly removed the child, subsequent to divorce, from a naturally or court-imposed joint custody arrangement, or a court has otherwise stated that one parent cannot make such decisions, or the parent's parental rights have been terminated. If, during a custody proceeding, a court does not award joint custody but instead renders one parent the domiciliary parent, the following rule applies: the domiciliary parent shall have authority to make all decisions, including healthcare decisions, affecting the child unless an implementation order provides otherwise. ${ }^{29}$ All major decisions made by the domiciliary parent concerning the child shall be subject to review by the court upon motion of the other parent. It shall be presumed that all major decisions made by the domiciliary parent are in the best interest of the child. ${ }^{29}$

However, under any circumstances, the consent of only one parent is necessary for medical decision-making. In the event of conflicting wishes, judicial intervention is possi- ble. If care is emergent, the provider should do what is clinically indicated for the child.

If a minor has been separated from the custody of his parents and needs surgical treatment, consent may generally be provided by the following entities: (1) persons standing in loco parentis of the minor, formally or informally; (2) judges, if the minor is under custody of their respective court; (3) Department of Child and Family Services; (4) Department of Corrections; and (5) officers of institutions or agencies legally qualified to receive the minor for care and maintenance.

\section{CONCLUSION}

The law and ethical doctrine still dictate that parental consent for the child prevails with allowance of the participation of the child in decision-making when appropriate. Providing age and developmentally appropriate information to patients is critical. The impact when the medical team and the decisionmaking authority differ may not always be fully understood by the decision-making party. However, physicians should resolve disagreements with time and education and not by forcing care. A consideration of medical ethics and law along with medical evaluation of the patient will help guide the physician, patient, and family education discussion to determine the best path forward in the care of a child.

\section{REFERENCES}

1. Sadovnikoff N. Fundamentals of informed consent. In: Jericho BG, Jacobs JS, eds. American Society of Anesthesiologists Committee on Ethics Syllabus. 2012:70-80. http://citeseerx.ist .psu.edu/viewdoc/download?doi=10.1.1.730 .3136\&rep=rep1\&type=pdf. Accessed December 10, 2015.

2. Carollo D, Waisel DB. Fundamentals of the pediatric informed consent process. In: Jericho BG, Jacobs JS, eds. American Society of Anesthesiologists Committee on Ethics Syllabus. 2016:17-21. https://www.asahq.org/ /media/sites/asahq/files/public /resources/asa\%20committees/syllabus-on-ethics.pdf?la=en. Accessed May 8, 2018.

3. Informed consent, parental permission, and assent in pediatric practice. Committee on Bioethics, American Academy of Pediatrics. Pediatrics. 1995 Feb;95(2):314-317.

4. Rhodes R, Holzman IR. Is the best interest standard good for pediatrics? Pediatrics. 2014 Oct;134 Suppl 2;S121-S129. doi: 10.1542/peds.2014-1394H.

5. Rhodes R, Holzman IR. The not unreasonable standard for assessment of surrogates and surrogate decisions. Theor Med Bioeth. 2004;25(4):367-385.

6. Veatch RM. Abandoning informed consent. Hastings Cent Rep. 1995 Mar-Apr;25(2):5-12.

7. Harrison C, Kenny NP, Sidarous M, Rowell M. Bioethics for clinicians: 9. Involving children in medical decisions. CMAJ. 1997 Mar 15;156(6):825-828.

8. Lewis CC. How adolescents approach decisions: changes over grades seven to twelve and policy implications. Child Dev. 1981 Jun;52(2):538-544.

9. Brock DW. Children's competence for health care decisionmaking. In: Kopelman LM, Moskop JC, eds. Children and Health Care: Moral and Social Issues. Dordrecht (Holland): Kluwer Academic Publishers; 1989:181-212.

10. Belcher $v$ Charleston Area Medical Center, 422 S.E.2d 827 (1992) 188 W.Va. 105. https://scholar.google.com/scholar_case ?case $=14842078072813819970 \& q=422+S E 2 d+827 \& h l=e n \& a s$ sdt=2,31. Accessed September 7, 2018. 
11. American Academy of Pediatrics Committee on Bioethics. Guidelines on foregoing life-sustaining medical treatment. Pediatrics. 1994 Mar;93(3):532-536.

12. Weithorn LA, Campbell SB. The competency of children and adolescents to make informed treatment decisions. Child Dev. 1982 Dec;53(6):1589-1598.

13. Diekema DS. Adolescent refusal of lifesaving treatment: are we asking the right questions? Adolesc Med State Art Rev. 2011 Aug;22(2):213-228, viii.

14. Committee on Pediatric Emergency Medicine and Committee on Bioethics. Consent for emergency medical services for children and adolescents. Pediatrics. 2011 Aug;128(2):427-433. doi: 10.1542/peds.2011-1166.

15. Judicial emancipation law. La. Civ. Code art. 366. http://legis.la .gov/Legis/Law.aspx?d=110582. Accessed September 7, 2018.

16. Petition for judicial emancipation law. La. Code Civ. P. arts. 3991 et seq. https://legis.la.gov/legis/Laws_Toc.aspx ?folder=68\&level=Parent. Accessed September 7, 2018.

17. Emancipation by marriage law. La. Civ. Code art. 367. https:/ /legis.la.gov/legis/Law.aspx?d=110583. Accessed September 7, 2018.

18. Fraudulent interference with parental consent law. La. RS 40:1061.14. http://legis.la.gov/legis/Law.aspx?d=965007. Accessed September 7, 2018.

19. Donation of blood law. La. RS 40:1079.3. http://legis.la.gov /Legis/Law.aspx?d=964347. Accessed September 7, 2018.

20. Medical treatment law. La. R.S. 40:1079.1. http://legis.la.gov /Legis/Law.aspx?p=y\&d=964338. Accessed September 7, 2018.
21. Persons who may consent to surgical or medical treatment law. La. RS 40:1159.4. http://legis.la.gov/Legis/Law.aspx?d=964700. Accessed September 7, 2018.

22. Emergencies law. La. RS 40:1159.5. http://legis.la.gov/Legis/Law .aspx?d=964701. Accessed September 7, 2018.

23. Treatment for drug abuse law. La. RS 40:1079.2. http://legis.la .gov/Legis/Law.aspx?d=964342. Accessed September 7, 2018.

24. Minor's consent for treatment of venereal diseases law. La. RS 40:1121.8. http://legis.la.gov/Legis/Law.aspx?d=964307. Accessed September 7, 2018.

25. Right of adult to refuse treatment as to his own person not abridged law. La. RS 40:1159.7. http://legis.la.gov/Legis/Law .aspx?d=964703. Accessed September 7, 2018.

26. Deprivation of medical or surgical care prohibited; exceptions law. La. Children's Code art 1554. http://legis.la.gov/Legis/Law .aspx?d=73012. Accessed September 7, 2018.

27. Certification of child's terminal status law. La. Children's Code art. 1555. http://legis.la.gov/Legis/Law.aspx?d=73013. Accessed September 7, 2018.

28. Definitions. La. Children's Code art. 603. http://legis.la.gov/Legis /Law.aspx?d=73195. Accessed September 7, 2018.

29. Joint custody decree and implementation order law. La. RS 9:335. http://legis.la.gov/Legis/Law.aspx?d=107527. Accessed September 7, 2018. 